\title{
Standardization of Switchgrass Sample Collection for Cell Wall and Biomass Trait Analysis
}

\author{
C. Frank Hardin • Chunxiang Fu • Hiroshi Hisano • \\ Xirong Xiao • Hui Shen • C. Neal Stewart Jr. • \\ Wayne Parrott • Richard A. Dixon • Zeng-Yu Wang
}

Published online: 17 January 2013

(C) The Author(s) 2013. This article is published with open access at Springerlink.com

\begin{abstract}
As a native, low-input crop with high biomass production, switchgrass (Panicum virgatum) has become a favorable feedstock for the production of cellulosic biofuels in the United States. Many efforts are being made to improve the production of cellulosic biofuels from switchgrass. Protocols regarding analysis of switchgrass biomass have been established; however, the developmental stage of the materials being analyzed has varied depending on researchers' discretion, and no standardized harvesting procedure has been defined. Developmental stages have a large impact on the results of biochemical analyses. We propose a standardized procedure for switchgrass sample collection for cell wall and biomass analyses by describing various developmental stages of switchgrass, defining the R1 stage
\end{abstract}

C. F. Hardin · C. Fu $\cdot$ H. Hisano $\cdot$ X. Xiao $\cdot$ Z.-Y. Wang $(\bowtie)$

Forage Improvement Division, The Samuel Roberts Noble

Foundation, 2510 Sam Noble Parkway,

Ardmore 73401 OK, USA

e-mail: zywang@noble.org

H. Shen • R. A. Dixon

Plant Biology Division, The Samuel Roberts Noble Foundation,

2510 Sam Noble Parkway,

Ardmore 73401 OK, USA

C. N. Stewart Jr.

Department of Plant Sciences, University of Tennessee,

2431 Joe Johnson Drive,

Tennessee 37996 TN, USA

W. Parrott

Department of Crop and Soil Sciences, The University of Georgia,

111 Riverbend Road,

Athens 30602 GA, USA

C. F. Hardin $\cdot$ H. Hisano $\cdot$ X. Xiao $\cdot$ H. Shen $\cdot$ C. N. Stewart Jr.

W. Parrott $\cdot$ R. A. Dixon $\cdot$ Z.-Y. Wang

BioEnergy Science Center, Oak Ridge National Laboratory,

Oak Ridge 37831 TN, USA as the stage at which tillers should be collected, and providing a detailed description of how and what material should be analyzed. Such a standardized procedure will help to maintain consistency in switchgrass evaluation methods, enable comparisons of data obtained from different approaches and studies, and facilitate efforts towards improving switchgrass as a bioenergy crop.

Keywords Switchgrass $\cdot$ Panicum virgatum $\cdot$ Sample collection $\cdot$ Developmental stage $\cdot$ Cellulosic biofuels

\section{Introduction}

Biofuels derived from non-grain lignocellulosic feedstocks with high biomass production are a promising source for renewable energy and have the potential to meet a significant portion of the world's transportation fuel demand with much less negative environmental impact than fossil fuels $[1,2]$. Switchgrass (Panicum virgatum) is a perennial, C4 warm-season grass native to North America. For years, it has been used for land conservation programs and as a forage crop due to its low agronomic input requirements and environmental benefits [3-5], and more recently, has been chosen as a favorable feedstock for the production of cellulosic biofuels by the US Department of Energy [6, 7].

Switchgrass is an erect, high biomass-producing bunchgrass that can reach heights of $4 \mathrm{~m}$. It grows as a 'clonal modular organism' [8] in which tillers, consisting of stem, nodes, internodes, leaf blade and sheath, axillary bud, and ligule, form the main growing module [3]. An individual plant is composed of a population of tillers at various vegetative and reproductive stages of development. Switchgrass is a highly self-incompatible, outcrossing species [5] with a diffuse panicle type seedhead containing spikelets arranged at the end of long branches [9]. 
Cellulose and hemicellulose in cell walls of switchgrass may be converted into fermentable sugars by enzymatic hydrolysis for the production of cellulosic ethanol. However, the plant cell wall is recalcitrant to hydrolysis due largely in part to the presence of lignin, which restricts access of hydrolytic enzymes to the polysaccharides, reducing sugar release and limiting conversion efficiency [10]. Transgenic approaches and breeding efforts integrating genomic technologies are currently being implemented to overcome switchgrass recalcitrance and improve the grass as a biofuel crop $[7,11,12]$. A major impediment for releasing transgenic switchgrass to the environment is the high cost of biosafety regulation. Regulatory agencies have raised special concerns and required additional scrutiny for outcrossing grasses [12].

Reliable and consistent phenotypic evaluation methods for biomass composition and processing efficiency are essential to accurately quantify gains from switchgrass improvement efforts. Previous studies have evaluated the biochemical and molecular characteristics (e.g., gene expression level, enzyme activity, lignin content/composition, sugar release, and ethanol production) of transgenic plants at different or sometimes undefined growth stages [13-16]. This ambiguity makes it difficult to compare results across studies because of possible developmental variations present in switchgrass. This situation is more problematic when considering the results of recent studies showing that the biochemical properties of switchgrass tillers vary not only at different developmental stages but also within different internodes and subdivisions of internodes [17, 18]. These problems are further exemplified by several reports in which discrepancies are even found in the labeling schemes of the internodes of tillers. The internodes are numerically labeled from the basal, oldest internode to the upper, youngest internode in Shen et al. [18] and Fu et al. [12], and from the youngest to the oldest in Sarath et al. [19] and Xu et al. [16]. Such discrepancies hinder accurate evaluation of the effects of genetic modification. Thus, the lack of standard methodologies toward the collection of biomass materials for biochemical and molecular analysis, determining biomass composition and quality, and evaluating processing efficiency, may impede efforts to improve these biofuel traits in switchgrass.

Currently, there is a large investment in genetic manipulation of switchgrass. Because of the need for analyzing a large number of samples, high-throughput analytical methods have been developed. Considering that a relatively small amount of material is required for these analyses, a defined method for sampling collection is needed. It is critical to sample at the same developmental stage; however, deciding which stage and what material of that stage to collect has been a difficult decision that has raised many practical problems, particularly for analyzing transgenic plants. After many preliminary experiments and analyses, we propose a relatively easy, standardized method of switchgrass sample collection for biochemical and molecular analysis so that efforts toward the improvement of switchgrass as a biofuel feedstock may be easily compared across studies.

\section{Materials and Methods}

\section{Sample Collection}

Switchgrass plants from the 'Alamo' cultivar genotype ST1 were potted in 11-L (3-gallon) pots with Sun Gro Horticulture Metro-Mix ${ }^{\circledR} 830$ soil and grown in the greenhouse at $27-29.4{ }^{\circ} \mathrm{C}$ with $16 \mathrm{~h}$ light $\left(390 \mu \mathrm{Em}^{-2} \mathrm{~S}^{-1}\right)$ per day and a relative humidity of 28-69\% (mean $53 \%$ ). Developmental stages of switchgrass were divided into five elongation (E1, E2, E3, E4, and E5) and three reproductive (R1, R2, R3) stages. E1 and subsequent elongation sub-stages are defined by the number of visible and palpable nodes present, as described by Moore et al. [20]. The emergence of the inflorescence from the boot stage marks the beginning of the reproductive stage (R1). The R2 stage is defined by fully emerged spikelets with no peduncle present. Fully emerged spikelets and an emerged peduncle differentiate the R3 stage (Fig. 1). Internodes are numerically labeled from the basal, oldest internode to the upper, youngest internode (Fig. 1b) as described by Shen et al. [18]. Tillers from E2, E3, E4, R1, $\mathrm{R} 2$, and R3 (E5 tillers were not harvested due to their rarity within this genotype) developmental stages were collected, and internode 1 (I1) and the top of the tiller (material above the youngest node) were removed. Stems from the remaining material were harvested by removing the leaf blades and sheath. The remaining stem was cut into $2-3-\mathrm{cm}$ pieces, collected in a paper bag, and then oven-dried for 7 days at $40{ }^{\circ} \mathrm{C}$.

Dried stem material was ground in a Wiley mill through a $0.8 \mathrm{~mm}$ screen. Soluble extracts were removed from samples by three successive extractions with chloroform/methanol $(2: 1 \mathrm{v} / \mathrm{v})$, methanol, and water at room temperature as described by Chen et al. [21], and the remaining cell wall residue (CWR) was lyophilized. The extractive-free CWR was then used to quantify lignin content, and for lignin composition and sugar release analysis.

\section{Determination of Lignin Content and Composition}

The acetyl bromide (AcBr) method described by Hatfield et al. [22] was used to quantify lignin content. Briefly, 20.5 \pm $0.1 \mathrm{mg}$ CWR was treated with $5 \mathrm{ml}$ of $25 \%(v / v)$ acetyl bromide in glacial acetic acid for $4 \mathrm{~h}$ at $50{ }^{\circ} \mathrm{C}$. After heating, the samples were cooled and centrifuged at 3,500 rpm for $15 \mathrm{~min}$, and $4 \mathrm{ml}$ of the top layer was transferred into a 
Fig. 1 Developmental stages of switchgrass. Various elongation $(E)(\mathbf{a})$ and reproductive $(R)$ stages $(\mathbf{b})$ of switchgrass tillers were collected and photographed. Arrowheads indicate visible and/or palpable nodes. Internodes 1-5 (I1-I5) and the peduncle are labeled on the R3 tiller
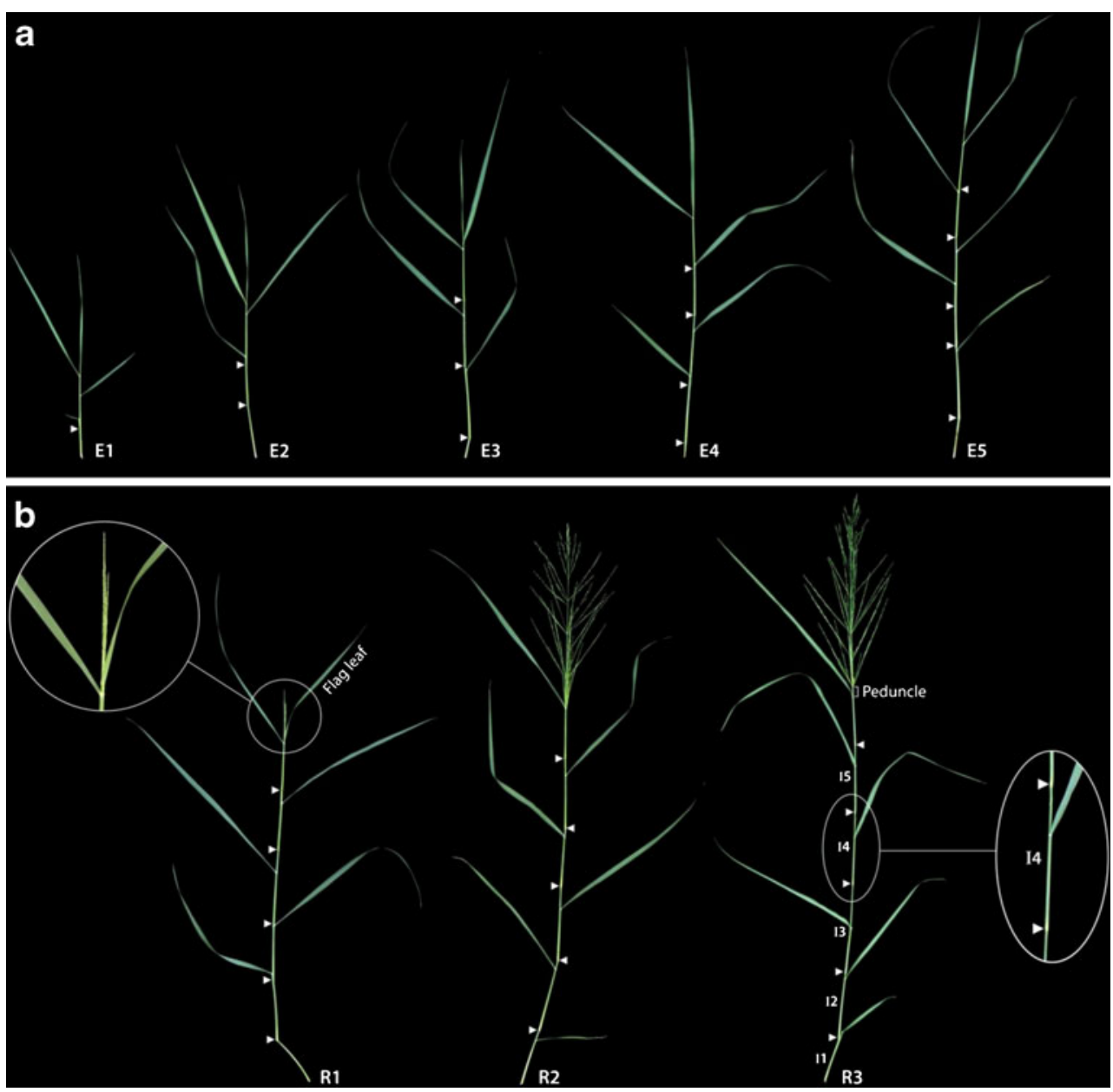

50 -mL volumetric flask containing $10 \mathrm{~mL}$ of $2 \mathrm{M} \mathrm{NaOH}$ and $12 \mathrm{~mL}$ of acetic acid. Hydroxylamine $(1 \mathrm{~mL}$ of $0.5 \mathrm{M})$ was added to each flask, and samples were diluted to $50 \mathrm{~mL}$ with acetic acid. Absorption spectra (250 to $350 \mathrm{~nm}$ ) were determined for each sample and used to determine the absorption maxima at $280 \mathrm{~nm}$. A molar extinction coefficient of 17.2 was used for all samples [21].

Lignin composition analysis was determined using the thioacidolysis method [23]. Briefly, 20.5 $\pm 0.1 \mathrm{mg}$ CWR was treated with $3 \mathrm{~mL}$ of $0.2 \mathrm{M}$ boron trifluoride etherate in an 8.75:1 dioxane/ethanethiol mixture for $4 \mathrm{~h}$ at $100{ }^{\circ} \mathrm{C}$. After cooling, deionized water and saturated sodium bicarbonate were added, and the organic solvent was extracted twice with methane chloride and dried with anhydrous sodium sulfate. The solvent was dried under $\mathrm{N} 2$ and derivatized by adding $25 \mu \mathrm{l}$ of pyridine and $80 \mu \mathrm{l} \mathrm{MSTFA} \mathrm{at} 37^{\circ} \mathrm{C}$ for $30 \mathrm{~min}$; $50 \mu \mathrm{l}$ was used for analysis. Lignin-derived monomers ( $\mathrm{S}, \mathrm{G}$, $\mathrm{H}$, and 5-OH G) were identified and quantified by gas chromatography-mass spectrometry using a Hewlett-Packard 5890 series II gas chromatograph with a 5971 series mass selective detector (column, HP-1, $60 \mathrm{~m} \times 0.25 \mathrm{~mm} \times 0.25-\mu \mathrm{m}$ film thickness). Mass spectra were recorded in electron impact mode $(70 \mathrm{eV})$ with $60-650 \mathrm{~m} / \mathrm{z}$ scanning range [13].
Total Sugar and Saccharification Efficiency Analysis

Total sugar analysis as modified from the analytical procedure of the National Renewable Energy Laboratory (LAP-002, "Determination of Structural Carbohydrate and Lignin in Biomass"; http://www.nrel.gov/biomass/ analytical_procedures.html\#lap-002) was used to determine total sugar yield from stems. Cell wall residue $(100 \pm$ $0.1 \mathrm{mg}$ ) was hydrolyzed in $72 \%$ sulfuric acid at $30{ }^{\circ} \mathrm{C}$ for $1 \mathrm{~h}$ in a $5-\mathrm{mL}$ glass scintillation vial. The vial was transferred to a 50-mL flask and washed with $42 \mathrm{~mL}$ deionized water before being autoclaved for $1 \mathrm{~h}$ at $121{ }^{\circ} \mathrm{C}$. The flasks were slowly cooled to $68{ }^{\circ} \mathrm{C}$, and the liquid was transferred to a $50-\mathrm{mL}$ tube. Deionized water $(10 \mathrm{~mL})$ was used to wash each flask and subsequently added to the previously collected material. The material was centrifuged at $4,000 \mathrm{rpm}$ for $30 \mathrm{~min}$, and the supernatant was transferred to a new tube. Solubilized total sugars were estimated by spectrophotometry using the phenol-sulfuric acid assay [24]. Briefly, $150 \mu \mathrm{l}$ of $5 \%$ phenol and $750 \mu \mathrm{L}$ concentrated sulfuric acid were added to each $100-\mu \mathrm{L}$ sample and heated for $30 \mathrm{~min}$ at $30^{\circ} \mathrm{C}$. Immediately after heating, the A480 was determined using an Evolution 300 UV-visible spectrophotometer and 
VISIONpro ${ }^{\mathrm{TM}}$ software (Thermo Electron Corporation, Madison, WI).

Saccharification efficiency analysis was performed as described by the National Renewable Energy Laboratory (LAP-009, "Enzymatic Saccharification of Lignocellulosic Biomass"; http://www.nrel.gov/biomass/analytical procedures.html) by digesting CWR (untreated), or CWR pretreated with dilute $\mathrm{H}_{2} \mathrm{SO}_{4}(1.5 \%)$ at $121{ }^{\circ} \mathrm{C}$ for $60 \mathrm{~min}$ and washed with water, with a cellulase and cellobiase mixture for $72 \mathrm{~h}$. Solubilized sugars were analyzed using the phenol-sulfuric acid assay. Saccharification efficiency was determined as the ratio of sugars released by enzymatic hydrolysis to the amount of total sugar present in the CWR prior to enzymatic hydrolysis [25].

\section{Measurement of Biomass}

Three stems from each developmental stage were harvested and dried, as previously described, and weighed.

\section{Histochemical Staining of Lignin}

Switchgrass internode samples from R1 stage tillers were collected in the greenhouse and immediately frozen in liquid nitrogen. The middle portions of internode 2 were cut into 30- $\mu \mathrm{m}$ sections with a Leica CM 1850 cryostat (Leica Microsystems Inc., Buffalo Grove, IL) at $-20{ }^{\circ} \mathrm{C}$ and prepared for lignin staining. Lignin was stained by phloroglucinol-HCL solution $(0.5 \% \mathrm{~g} / \mathrm{ml})$ for $1 \mathrm{~min}$ followed by HCL and glycerol solution (1:1) for 2 min. Photographs were taken using a Nikon microphot-FX microscope system with ACT-1 software (Nikon Instruments Inc., Laguna Hills, CA).

\section{Statistical Analysis}

Triplicate samples were collected for each developmental stage. Data from each trait were subjected to analysis of variance. The significant differences between treatments were tested at the $p<0.05$ level using Duncan's test. Standard errors are provided in all figures. All statistical analyses were performed using the SPSS package (SPSS Inc., Chicago, IL).

\section{Results and Discussion}

A general method for identifying the different developmental stages of perennial forage grasses was described by Moore in 1991 [20]. We have applied this method specifically to switchgrass in order to provide a more convenient, standard identification criterion. Various elongation and reproductive stages of switchgrass tillers are depicted (Fig. 1) in an effort to facilitate identification of the desired developmental stages and ensure sampling consistency.

To determine if some of the biochemical properties of greenhouse-grown switchgrass that relate to biomass processing vary at different developmental stages, we examined the lignin content (Fig. 2a), lignin monomer composition (Fig. 2b), total sugar (Fig. 2c), saccharification efficiency (Fig. 2d) and biomass (Fig. 2e) of E2-4 and R1-3 stems. Stems were analyzed because they comprise a large proportion of the total tiller biomass and contain higher lignin content compared with the other tissues (leaf, leaf sheath, and inflorescence) [18]. As the tillers mature from the E3 to the R2 stage, lignin content in the stem increases (Fig. 2a). After analyzing lignin monomer composition, we found that the $\mathrm{S} / \mathrm{G}$ ratio also increases as the tillers develop (Fig. 2b). Analysis of total sugar content of the CWR, important when calculating saccharification efficiency which is commonly used to evaluate the acceptability of plant material for bioconversion to products, shows that total sugar content increases as the tillers develop (Fig. 2c), and saccharification efficiency decreases in both untreated and pretreated samples (Fig. 2d). Furthermore, the dry weight of the stems also increased with age (Fig. 2e). Histochemical staining of $\mathrm{R} 1$ internode with acid phloroglucinol illustrated lignin accumulation pattern at this developmental stage (Fig. 2f). Histochemical staining of internodes at various developmental stages (data not shown) indicated that lignin deposition increased with progressive maturity, consistent with the biochemical data. The maturation effect on cell wall composition observed in this study is consistent with reports on other grass species [26, 27]. Collectively, the data indicate that these biochemical properties vary among stems at different developmental stages (Fig. 2a-e), and it is likely that other biochemical traits may vary as well. Therefore, if samples are collected from different stages, a comparison of data may not be appropriate; thus, a specific developmental stage for sample collection must be defined so that data can be comparable across studies. When deciding which material to use for analysis, the most important criteria were that the material be easily identifiable and representative of most tissues in the harvested biomass, and that the collection method be easily adoptable by different labs. Of the various developmental stages, the R1 stage was the easiest to visually identify due to the presence of inflorescence. However, because the terminal length of inflorescence in the R1 stage may vary, we specify that the R1 stage have an emerged inflorescence length of approximately $5 \pm 2.5 \mathrm{~cm}$ when collecting samples. In some cases, we have observed that inflorescence length may exceed the defined length while encased in the leaf sheath. If the plants are monitored closely, this material may be harvested once the inflorescence becomes visible. 

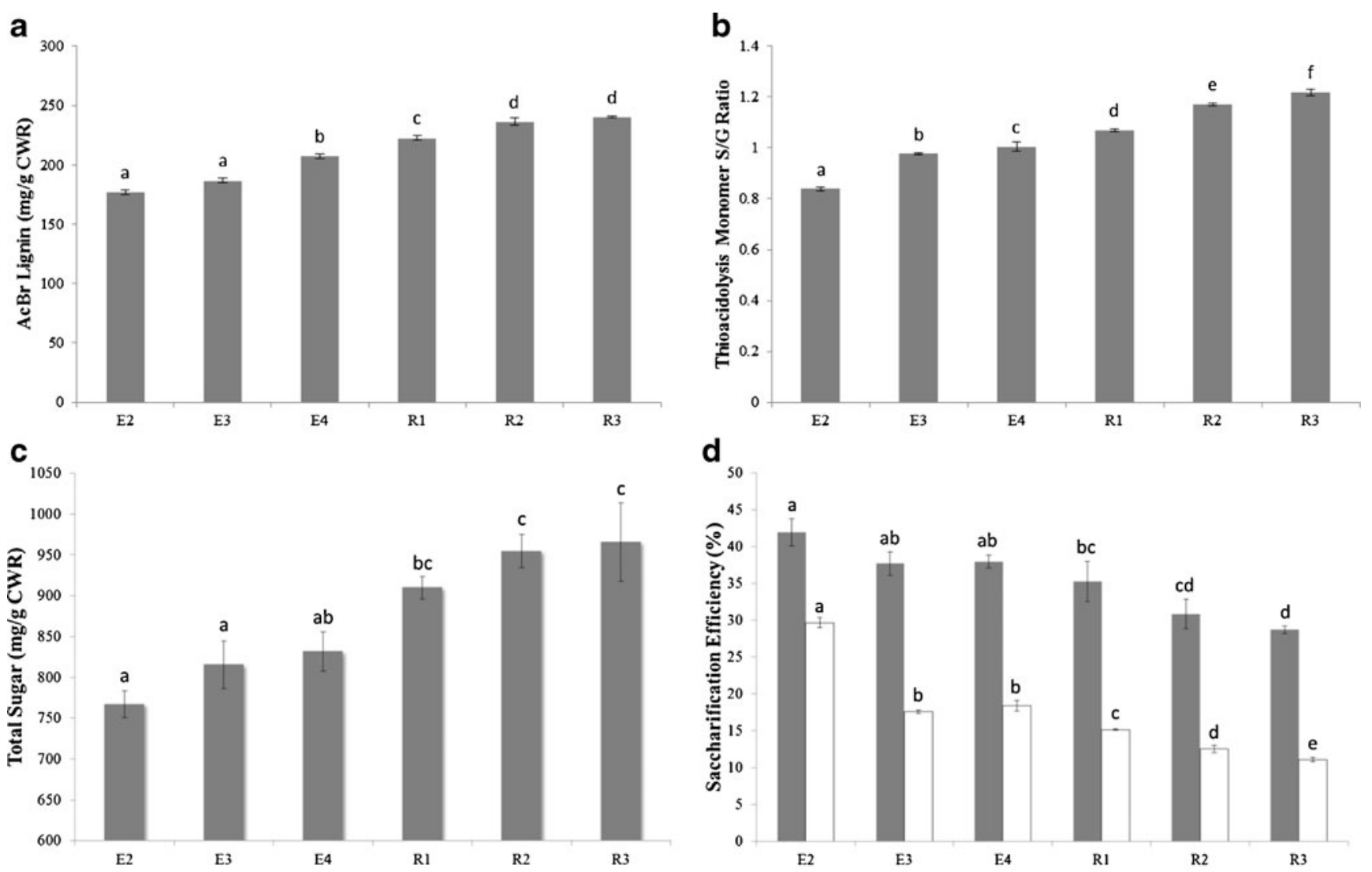

$\mathbf{d}_{50}$

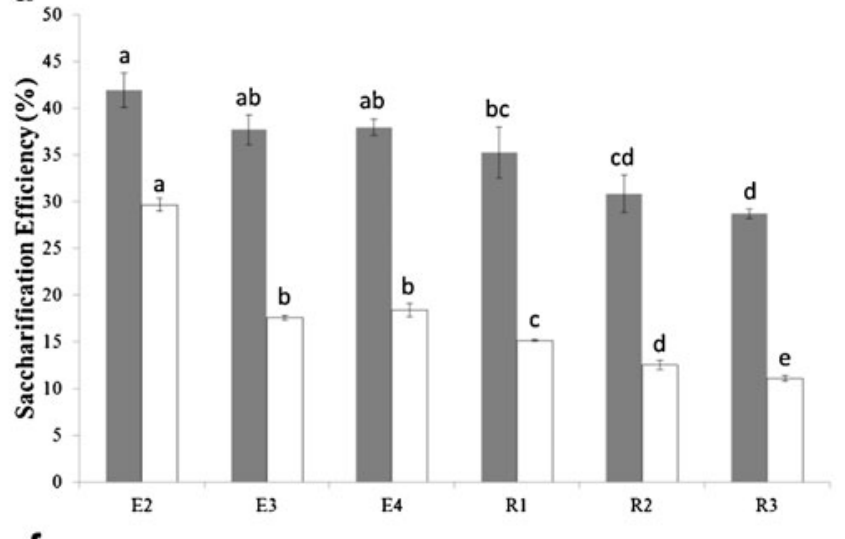

e

$\mathbf{f}$
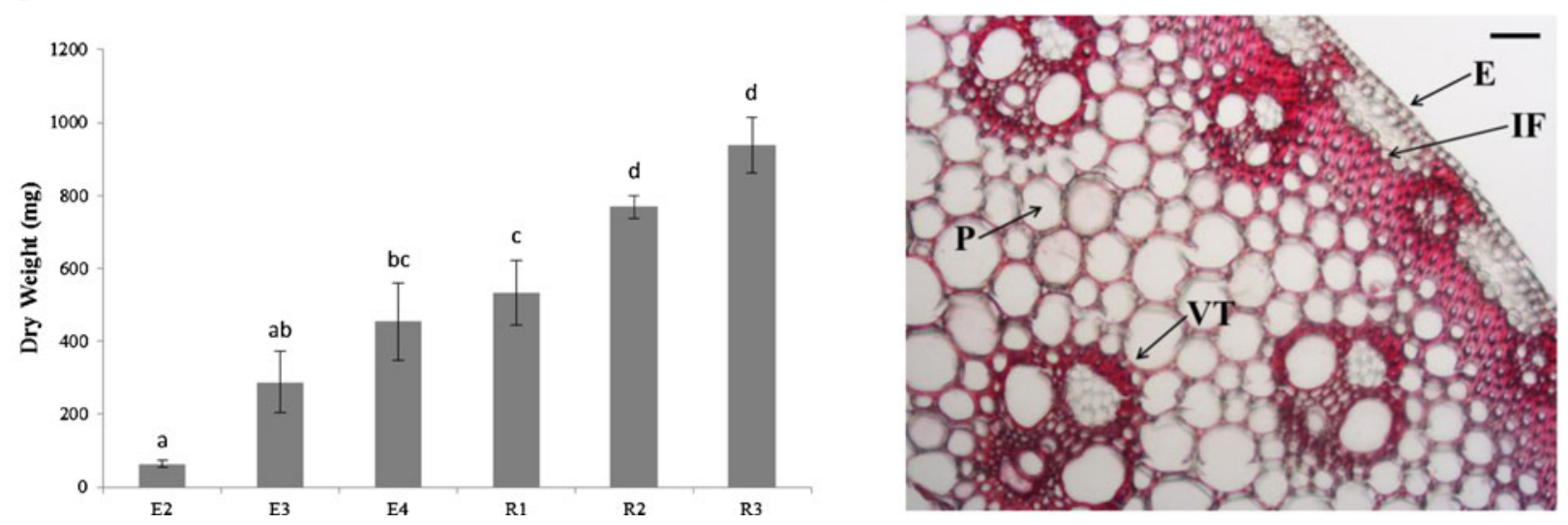

Fig. 2 Cell wall and biomass trait analysis of switchgrass stems at different developmental stages. Stems from greenhouse-grown, clonally propagated 'Alamo' ST1 plants were collected at different developmental stages ( $x$-axis), dried, and then ground, and the CWR was extracted. AcBr lignin content (a), lignin monomer composition (b), total sugar content (c), and saccharification efficiency (filled square pretreated, empty square untreated) (d) were analyzed. Stems from each developmental stage ( $x$-axis) of greenhouse-grown plants

While collecting samples, we have observed that each tiller will eventually reach the R1 stage. Most of these tillers will reach the $\mathrm{E} 4$ or $\mathrm{E} 5$ stage before progressing into R1; however, some may only reach E3. This variation makes sample collection at any of the elongation stages difficult. Therefore, aside from being easy to identify, another

were collected, dried, and then assayed for biomass (e). Bars labeled with the same letters are not significantly different at $p=0.05$. Values are means \pm standard error $(n=3)$. $C W R$ cell wall residue, $S$ syringyl lignin monomer, $G$ guaiacyl lignin monomer. Lignin from the middle section of internode 2 from R1 stage stems was stained with phloroglucinol- $\mathrm{HCl}$ and photographed at $\times 100$ magnification (bars, $50 \mu \mathrm{m})(\mathbf{f}) . E$ epidermis, $I F$ interfascicular fiber, $V T$ vascular tissue, $P$ parenchyma cell

advantage of collecting at the R1 stage is that it reduces any ambiguity that may arise from collecting samples during the elongation stage. Finally, because switchgrass is a windpollinated species with a high degree of self-incompatibility, the potential for pollen-mediated gene flow is high $[12,28]$. Therefore, the regulatory requirement for the containment of 
flowering transgenic switchgrass is high; even in a contained greenhouse, it is preferred that flowering is limited and secondary containment measures (e.g., manual bagging over all flowers) be utilized. Although the biochemical properties of switchgrass stems peak at the later reproductive stages (R2 and R3, Fig. 2a-d), sample collection at the $R 1$ stage precedes these later reproductive stages ( 2 and R3) that may raise biosafety issues associated with the flowering of transgenic plants, and therefore simplifies the need for greenhouse containment measures.

As individual plants are produced for biochemical and molecular analysis, it is important to have biological replicates to strengthen the confidence of conclusions derived from experiments. Therefore, when the plants have approximately 20-25 tillers, they should be divided into four identical copies (daughter plants) each with approximately five tillers (the number of tillers per copy should be similar, but does not have to be exact). Three copies are then potted into 7.6-11-L (3-gallon) pot for sample collection and analysis, and one in an 11-L (3-gallon) pot for crossing (Fig. 3). It is important that plants are repotted at the same time and are the same age during sampling to avoid any developmental or environmental variations that may occur as the plants age. If transgenic plants are produced, leaf or stem tissues may be collected and analyzed by qRT-PCR prior to splitting to identify those with the greatest downregulation or transgene expression. In order to accurately assess the effect of the transgene on cell wall and biomass traits, emptyvector transgenic plants, derived from the same genotype as the experimental plants, should be produced and used as controls.

As tillers reach the R1 stage, the tiller should be removed by cutting below the first node. From this material, either whole tillers or stems may be harvested by removing I1 and the top of the tiller, or I1, the top of the tiller, and leaf sheaths and blades, respectively. By harvesting whole tillers or stems as opposed to individual internodes, the amount of material available for analysis increases and more closely mimics practical field harvesting methods (i.e., hay swathers and balers harvest the entire tiller). While whole tillers more closely represent material that is collected by field harvesting, we propose to analyze stems because it is easy to detect transgene effects in stems; they are the major organs for lignin deposition (i.e., they contain more lignin than leaves) [18], and they produce more ethanol by weight than whole tillers [13]. Stems may be analyzed to determine target gene expression, enzyme activity, lignin content and composition, polysaccharide composition, phenolic composition, sugar release efficiency, ethanol production, and forage digestibility (in vitro dry matter digestibility (IVDMD)). Whole tillers may be analyzed to determine sugar release, lignin content, ethanol production, and forage digestibility. More specifically, phenolic composition refers the concentration of $p$-coumaric acid, a major component of lignin biosynthesis, and ferulic acid, which is involved in crosslinking polysaccharides to lignin and function as nucleation sites for lignin formation [29, 30]. Because switchgrass can be used as a dual-purpose (biofuel/forage) crop, it is also

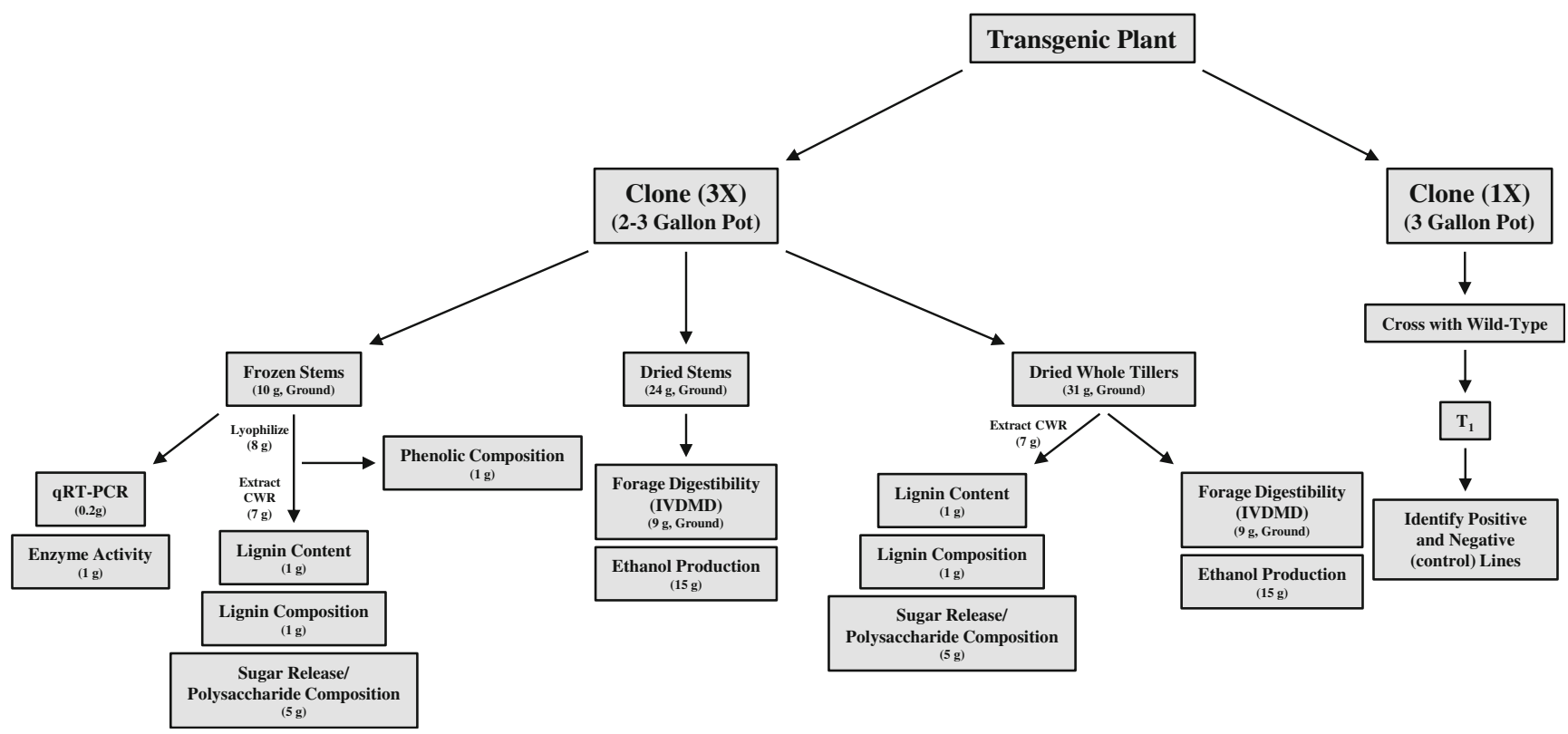

Fig. 3 Schematic diagram outlining the various analyses that may be done for stems collected at the R1 stage. The minimum amount of material required for each type of analysis is in parentheses and does not account for material lost during lyophilization or cell wall residue

extraction. Phenolic composition refers to assays that may be done to determine the concentration of chlorogenic, $p$-coumaric, caffeic, and ferulic acid 
important to analyze forage digestibility (IVDMD) in addition to biofuel traits.

The flow chart in Fig. 3 illustrates the entire experimental procedure in a simple, easy-to-follow manner and indicates what we have determined to be the amount of material required for most standard biochemical analyses.

After each whole tiller or stem is harvested, it should be immediately cut into $2-3-\mathrm{cm}$ pieces, collected in a $50-\mathrm{mL}$ disposable plastic tube and submerged in liquid nitrogen; frozen material should be stored at $-80^{\circ} \mathrm{C}$. Material to be dried should be collected in a paper bag. A minimum of $10 \mathrm{~g}$ of frozen and $24 \mathrm{~g}$ of dried material should be collected to ensure there is sufficient sample for downstream analysis. Tissue samples from a population of transgenic plants should be collected at the same time to enable identification of genetic differences in biochemical traits from each plant, rather than variation due to sampling times.

Many efforts are being made to improve switchgrass as a bioenergy crop. Methods regarding analysis of switchgrass biomass have been established; however, until now, the biomass materials being analyzed have been defined by the researchers' discretion. Herein, we have described a standardized procedure for switchgrass sample collection for biochemical and molecular analysis by describing various developmental stages of switchgrass, defining the R1 stage as the stage at which tillers should be collected and providing a detailed description of how and what material should be analyzed (Fig. 3). The availability of a standardized procedure for switchgrass sampling will be valuable for maintaining consistency in switchgrass evaluation methods, facilitate efforts towards improving switchgrass as a bioenergy crop, and enable comparisons of data obtained from different approaches and studies.

Acknowledgments The authors thank Scott McNeill, Katie Brown, and Cuc Ly for their help with the figures. This work was supported by the BioEnergy Science Center and The Samuel Roberts Noble Foundation, Inc. The BioEnergy Science Center is a U.S. Department of Energy Bioenergy Research Center supported by the Office of Biological and Environmental Research in the DOE Office of Science.

Open Access This article is distributed under the terms of the Creative Commons Attribution License which permits any use, distribution, and reproduction in any medium, provided the original author(s) and the source are credited.

\section{References}

1. Abramson M, Shoseyov O, Shani Z (2010) Plant cell wall reconstruction toward improved lignocellulosic production and processability. Plant Sci 178:61

2. DOE. Genomics:GTL Roadmap: Systems Biology for Energy and Environment, available online at http://genomicsgtl. energy.gov/roadmap. Germantown, MD: U.S. Department of Energy; 2005.
3. Bouton JH (2007) Molecular breeding of switchgrass for use as a biofuel crop. Curr Opin Genet Dev 17:553

4. Schmer MR, Vogel KP, Mitchell RB, Perrin RK (2008) Net energy of cellulosic ethanol from switchgrass. Proc Natl Acad Sci U S A 105:464

5. Vogel K. Switchgrass(2004). In: Moser LE, Burson BL, Sollenberger LE, editors. Warm-season (C4) grasses: American Society of Agronomy, p. 561.

6. McLaughlin SB, Kszos LA (2005) Development of switchgrass (Panicum virgatum) as a bioenergy feedstock in the United States. Biomass Bioenerg 28:515

7. Casler MD, Tobias CM, Kaeppler SM, Buell CR, Wang Z, Cao P et al (2011) The switchgrass genome: tools and strategies. The Plant Genome 4:273

8. Boe A, Casler MD (2005) Hierarchical analysis of switchgrass morphology. Crop Sci 45:2465

9. Moser L, Vogel KP (1995) Forages, an introduction to grassland agriculture. Ames. In: Barnes R, Miller DA, Nelson CJ (eds) Switchgrass, big bluestem, and indiangrass. Iowa State University Press, Iowa, p 409

10. Dien BS, Jung HJG, Vogel KP, Casler MD, Lamb JFS, Iten L et al (2006) Chemical composition and response to dilute-acid pretreatment and enzymatic saccharification of alfalfa, reed canarygrass, and switchgrass. Biomass Bioenerg 30:880

11. Hisano H, Nandakumar R, Wang ZY (2009) Genetic modification of lignin biosynthesis for improved biofuel production. In Vitro Cell Dev-P1 45:306

12. Wang Z-Y, Brummer EC (2012). Is genetic engineering ever going to take off in forage, turf and bioenergy crop breeding? Annals of Botany 110:1317

13. Fu C, Mielenz JR, Xiao X, Ge Y, Hamilton CY, Rodriguez M Jr et al (2011) Genetic manipulation of lignin reduces recalcitrance and improves ethanol production from switchgrass. Proc Natl Acad Sci U S A 108:3803

14. Fu C, Xiao X, Xi Y, Ge Y, Chen F, Bouton J, et al. Downregulation of cinnamyl alcohol dehydrogenase (CAD) leads to improved saccharification efficiency in switchgrass. Bioenerg Res 2011:1

15. Saathoff AJ, Sarath G, Chow EK, Dien BS, Tobias CM (2011) Downregulation of cinnamyl-alcohol dehydrogenase in switchgrass by RNA silencing results in enhanced glucose release after cellulase treatment. PLoS One 6:e16416

16. Xu B, Escamilla-Trevino LL, Sathitsuksanoh N, Shen Z, Shen H, Zhang YH et al (2011) Silencing of 4-coumarate:coenzyme A ligase in switchgrass leads to reduced lignin content and improved fermentable sugar yields for biofuel production. New Phytol 192:611

17. Massé D, Gilbert Y, Savoie P, Bélangerb G, Parent G, Babineauc D (2010) Methane yield from switchgrass harvested at different stages of development in Eastern Canada. Bioresour Technol 101:9536

18. Shen H, Fu C, Xiao X, Ray T, Tang Y, Wang Z et al (2009) Developmental control of lignification in stems of lowland switchgrass variety Alamo and the effects on saccharification efficiency. Bioenerg Res 2:233

19. Sarath G, Baird LM, Vogel KP, Mitchell RB (2007) Internode structure and cell wall composition in maturing tillers of switchgrass (Panicum virgatum. L). Bioresour Technol 98:2985

20. Moore KJ, Moser LE, Vogel KP, Waller SS, Johnson BE, Pedersen JF (1991) Describing and quantifying growth stages of perennial forage grasses. Agron J 83:1073

21. Chen F, Dixon RA (2007) Lignin modification improves fermentable sugar yields for biofuel production. Nat Biotechnol 25:759

22. Hatfield RD, Grabber J, Ralph J, Brei K (1999) Using the acetyl bromide assay to determine lignin concentrations in herbaceous plants: some cautionary notes. J Agric Food Chem 47:628 
23. Lapierre C, Pollet B, Rolando C (1995) New insights into the molecular architecture of hardwood lignins by chemical degradative methods. Res Chem Intermed 21:397

24. DuBois M, Gilles KA, Hamilton JK, Rebers PA, Smith F (1956) Colorimetric method for determination of sugars and related substances. Anal Chem 28:350

25. Fu C, Sunkar R, Zhou C, Shen H, Zhang JY, Matts J et al (2012) Overexpression of miR156 in switchgrass (Panicum virgatum L.) results in various morphological alterations and leads to improved biomass production. Plant Biotechnol J 10:443

26. Rancour D, Marita J, Hatfield RD (2012) Cell wall composition throughout development for the model grass Brachypodium distanchyon. Frontiers in Plant Science 2012;3
27. Chen L, Auh C, Chen F, Cheng XF, Aljoe H, Dixon RA, Wang Z-Y (2002) Lignin deposition and associated changes in anatomy, enzyme activity, gene expression and ruminal degradability in stems of tall fescue at different developmental stages. J Agri Food Chem 50:5558

28. Ge Y, Fu C, Bhandari H, Bouton J, Brummer EC, Wang Z-Y (2011) Pollen viability and longevity of switchgrass ( L.). Crop Sci 51:2698

29. Hatfield RD, Ralph J, Grabber JH (1999) Cell wall structural foundations: molecular basis for improving forage digestibilities. Crop Sci 39:27

30. Boerjan W, Ralph J, Baucher M (2003) Lignin biosynthesis. Ann Rev Plant Biol 54:519 